\title{
Phylae and Demes in Graeco-Roman Egypt.
}

In the descriptions of persons which occur so frequently in Greek papyri, there are several instances of a formula which has not hitherto been fully explained. To the name of the individual is added, besides the statement of his parentage, a pair of epithets connected by the

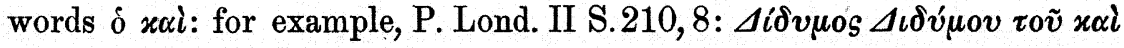

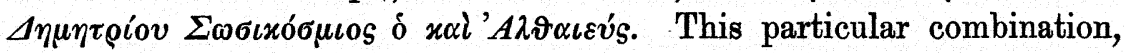

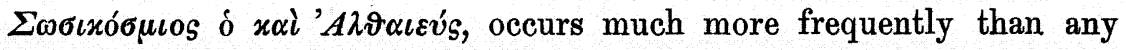
other, at least 22 examples of it being already known (see list below);

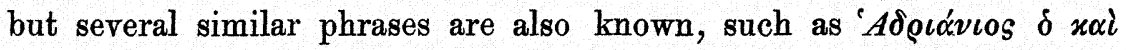

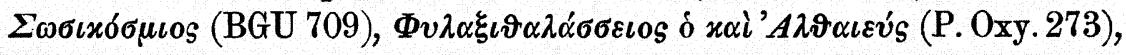
$A \grave{v} \xi \iota \eta \eta \tau$ ó nation is that given by Wilcken (Gött. gel. Anz. 1895, no. 2, p. 142), that they are names of demes, which have for some unexplained reason

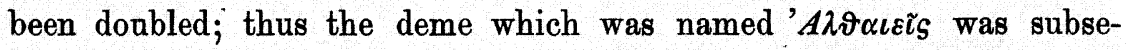

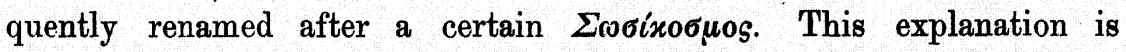
adopted by Grenfell and Hunt (P. Oxy. 243, P. Amh. 85, etc.), and no other, so far as I know, has been offered.

The explanation appears to be true, to the extent that a demename is contained in these descriptions, but false in supposing the two epithets to be alternative names of the deme. Attention may be called in the first place to evidence which has been available for some time. In BGU 578, 1. 4 a certain Lucius Antonius Minor, a citizen

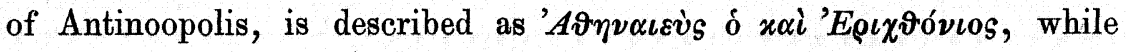
in an inscription from the same city (CIG III. 4705) the Prytanis of the $\beta o v \lambda \dot{\eta}$, Aurelius Origenes, is described as being $\varphi v \lambda \eta \tilde{s}$ ' $A \vartheta \eta v \alpha i \delta o s$. The comparison of these two passages suggests that in all cases of such double names, the first stands for the tribe $\left(\varphi v \lambda \eta^{\prime}\right)$, the second for the deme. Confirmation of this explanation is found in an unpublished papyrus in the British Museum (P. Lond. 1164). The papyrus consists of ten documents, originally separate, but fastened 
together to form a continuous roll. All are dated in the month Panemus-Pharmuthi in the $20^{\text {th }}$ year of the emperor Caracalla [= April, A. D. 212], and relate to pecuniary transactions (repayment of loans, purchases of houses, etc.), conducted through the bank of Anubion in Antinoopolis. In the course of these documents, double names of the type above described occur no less than 60 times. In col. $6,11.4,5$, the following description of one of the parties to a sale occurs: 'A $A$ -

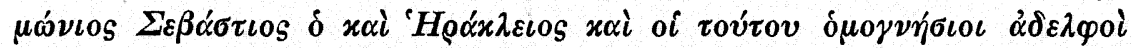

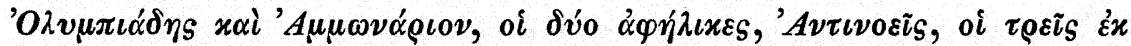

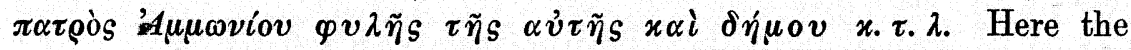
last words plainly refer to the preceding description, $\Sigma \varepsilon \beta \alpha \dot{\alpha} \sigma \tau \iota \mathrm{os} \delta x \alpha i$

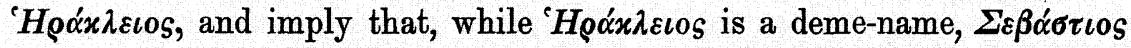
is a tribe-name. To this it may be added that in col. 1, which is

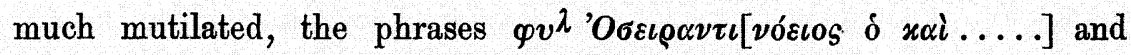

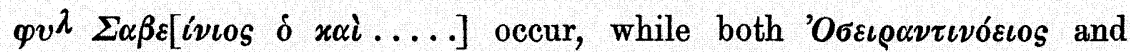
$\Sigma \alpha \beta \varepsilon i v i o s$ are found elsewhere as first elements in double names of the kind under investigation.

From this papyrus, accordingly, we can recover the names of nine tribes and twenty-seven demes of Antinoopolis, while, by a fortunate accident, a tenth tribe-name, with two deme-names, is preserved in two Berlin papyri. Whether the city had more than ten tribes, we have no means of knowing; but it is quite possible that it followed the example of Athens in her best days, and in that case we have a complete record of its tribal organisation. The list follows, in alphabetical order, together with the names of the demes assignable to each tribe. Except in the case of the first tribe, the evidence for all these names occurs in P. Lond. 1164; but in four instances corroborative evidence is furnished by other papyri.

\begin{tabular}{|c|c|}
\hline$\Phi v \lambda \dot{\eta}$. & $\Delta \tilde{\eta} \mu \mathrm{s}$. \\
\hline 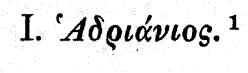 & 1. $\left.K \alpha \pi \iota \tau \omega \lambda \iota \varepsilon \dot{v}{ }^{1}{ }^{1}\right)$ \\
\hline 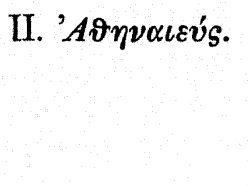 & 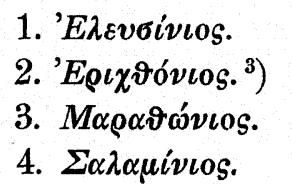 \\
\hline
\end{tabular}

1) BGU 301, I. 2.

2) $\mathrm{BGU} 709,1.24$.

3) Also in BGU $578,1.4$. 


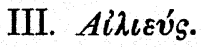

IV. Mazídıos.

V. Ne@ovıávıos.
1. $A \pi . . \varepsilon v_{S}$.

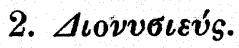

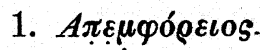

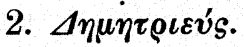

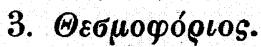

4. $K \alpha \lambda \lambda \iota \tau \varepsilon ́ x \nu \iota \circ$.

5. Ma@xเóv[l]os.

1. $\Gamma \varepsilon \nu \varepsilon-$

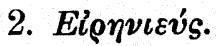

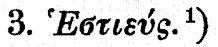

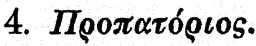

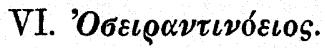

VII. $\Pi \alpha v \lambda i v i o s$.

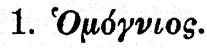

2. $\Phi \iota \lambda \alpha \delta \varepsilon^{\prime} \lambda \varphi \iota \circ$.

VIII. $\Sigma \alpha \beta$ sivııs.

1. $A \rho \mu-$

2. $\left.\Gamma \alpha \mu \eta \lambda \iota \varepsilon v_{s .}{ }^{2}\right)$

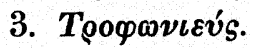

4. - $\tau \alpha \lambda \iota \varepsilon v_{S}$.

IX. $\Sigma \varepsilon \beta \alpha^{\prime} \sigma \tau \iota$ s.

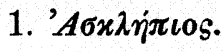

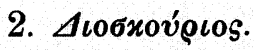

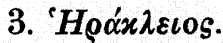

4. $K \alpha \iota \sigma \alpha ́ \rho \iota .^{3}$ )

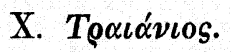

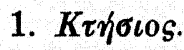

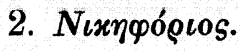

The names of these tribes explain themselves readily. Four are derived from the names of Hadrian himself, Ai'd $\Sigma \varepsilon \beta \alpha \sigma \tau o ́ s . \quad T \varrho \alpha \iota \alpha ́ v \iota o s$ also recalls his predecessor, Trajan, and $N \varepsilon \varrho o v \iota-$ $\alpha$ ' $\nu$ os the predecessor of Trajan, Nerva. $\Sigma \alpha \beta \varepsilon i \nu \iota_{s}$ is derived from

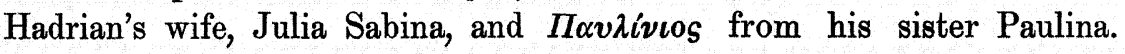

1) Also in BGU 300, 1. 2, where read $N \varepsilon[\varrho o v]\llcorner\alpha$ vios for Wilcken and Krebs' $N \varepsilon[o \alpha \delta] \rho \iota \alpha^{\prime} \nu$ ios. The reading of the deme-name, given by Wilcken-Krebs as

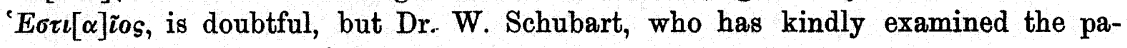

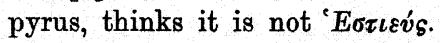

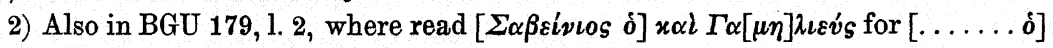
$x \alpha i \Gamma \alpha[\lambda \eta] \nu \varepsilon v$ s, the reading of Krebs and Wilcken.

3) Also in BGU 179, ll. 3, 4. 
Matidia, mother of Julia Sabina, gives her name to the tribe Maridıos.

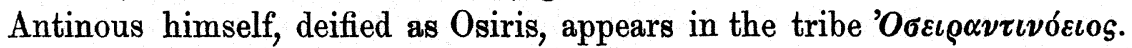
In this connection it may be noted that, since the Greeks equated Osiris and Dionysus (Herod. II. 144), the many representations of Antinous as Dionysus ${ }^{1}$ ) may equally be regarded, from the Egyptian point of view, as representations of him as Osiris; and the same identification may be intended in the pair of Egyptian statues from Hadrian's Villa at Tivoli (now in the Vatican), which have been generally regarded as portraits of Antinous in the character of an Egyptian deity. ${ }^{2}$ ) Finally the tribe' $A \vartheta \eta v \alpha$ is is a tribute to the avowedly Greek character of Hadrian's new foundation, and to Hadrian's fondness for Athens.

A similar attempt at appropriateness may be seen in many of

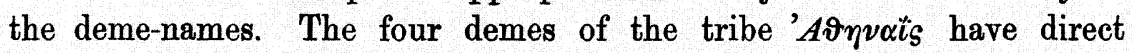
and obvious connections with Athenian history and mythology. Karı$\tau \omega \lambda \iota \varepsilon v^{\prime}$ and $\Sigma \omega \sigma \iota x \delta \sigma \mu \iota s$ are obvious compliments to the founder of

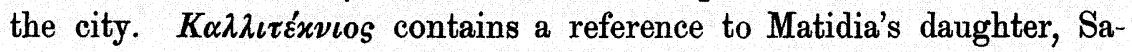
bina, and Mo@xióvios to her mother, Trajan's sister, Marciana. The four deme-names in the tribe Nepoviavia appear to allude to the pacific and paternal character of that emperor; the mutilated name

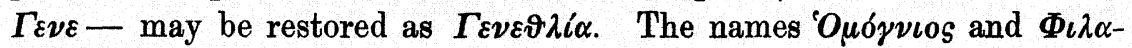
$\delta \varepsilon \dot{\lambda} \phi \iota_{\text {s }}$ are appropriate in the tribe called after Hadrian's sister, and $\Gamma \alpha \mu \eta \lambda \iota \varepsilon v_{s}$ in that which bears the name of his wife. Finally $K \tau \dot{\eta} \sigma \sigma_{0}$

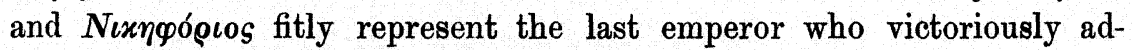
vanced the borders of the Roman empire. The remaining names are more ordinary, and have no special significance.

Apart from Antinoopolis, a considerable number of tribeand deme-names are known, of which it will be useful to give a list. ${ }^{3}$ ) I place first the cases in which both names are preserved, and afterwards a complete alphabetical list of deme-names, which references to the sources to which we owe our knowledge of them. In the spelling

1) See K. Levezow, Über den Antinous dargestellt in den Kunstdenkmälern des Altertums (Berlin, 1808), pp. 84-99.

2) Ib. pp. 123-126.

3) For this part of my paper I am under great obligations to Dr. W. Crö nert, who has supplied many of the references, especially those to the Bulletin de Correspondence Hellénique. Dr. Crönert had already prepared an article for the Archiv on this subject, giving a list of the extant deme-names; but on learning the new light thrown upon the subject by the British Museum papyrus, he most generously placed all his material at my disposal, in order that my list might be as complete as possible. Several references are also given by Lumbroso, L'Egitto dei Greci e dei Romani (1895), p. 74, note 2. 
of the names I have followed the scribes, or (when they differ) what appears to be the predominant usage; but in the case of the termination - $\varepsilon l o s$ or -105 there is evidently no uniformity or consistency in their practice.

\section{$\Phi v \lambda \eta^{\prime}$}

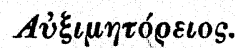

$\Delta \iota$ vv́бıs (at Alexandria) ${ }^{1}$ )
$\Delta \tilde{\eta} \mu o s$.

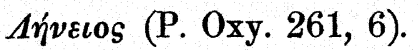

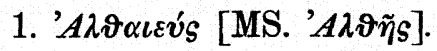
2. 'A
3. $\triangle \eta \iota \alpha \nu \varepsilon\left\llcorner\varrho \varepsilon v_{S}\right.$ [MS. $\left.-\tilde{\eta}_{s}\right]$.
4. Ev่ $\alpha v \vartheta \varepsilon v ́ s$.

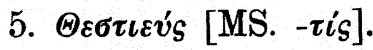

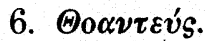

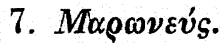
8. $\Sigma \tau \alpha \varphi v \lambda \varepsilon v ́ s$.

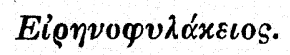

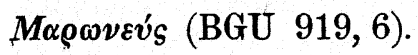

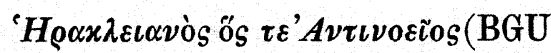
$710,25) \cdot{ }^{2}$ )

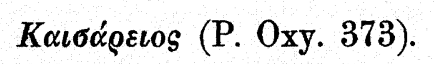

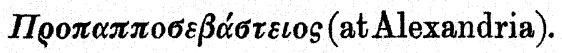

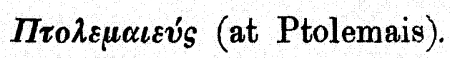

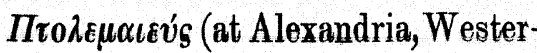
mann, Vit. script. gr. min., p. 50,

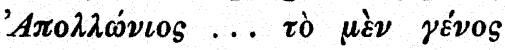

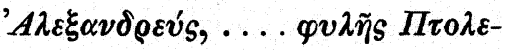

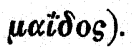

Eiגelovios (? see below).

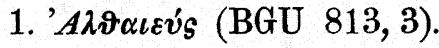

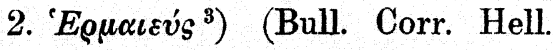
XX. 398).

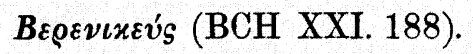

1) This tribe, with its demes, is mentioned by Satyros (frag. 21 in Müller's Fragg. Hist. Graec.). There is nothing to show whether the tribe-name was formed with the termination $-\varepsilon v s$ or -os, but the latter is more usual in the case of tribes.

2) If the reading is correct (and it is followed by $\delta x$, which indicates

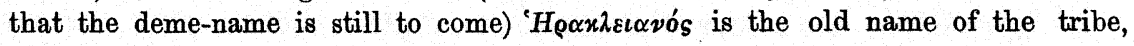
which had been renamed after Antinous in the reign of Hadrian, shortly before the date of this papyrus (A. D. 146/7).

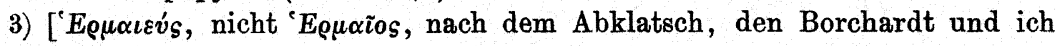
1898 von dem von uns wieder ausgegrabenen Stein in Menshîje (Ptolemais) genommen haben. D. Red.] 
F. G. Kenyon: Phylae and Demes in Graeco-Roman Egypt.

$\Sigma$

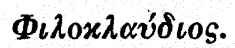

$\Phi v \lambda \alpha \xi \iota \vartheta \alpha \lambda \alpha \sigma \sigma \varepsilon \iota$ s (cf. also P.Leipz. 10, 1. 3: $\varphi v \lambda \alpha \xi \iota \vartheta \alpha \lambda \alpha \sigma^{\prime} \sigma \iota \nu\langle ? \tau \dot{v} v\rangle$

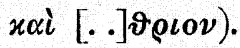

$[.] \iota \lambda \alpha \nu \alpha \beta \alpha^{\prime} \tau \varepsilon \iota 0$. $\left.{ }^{1}\right)$

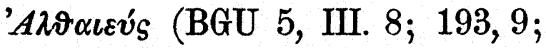
$427,8,26 ; 469,1 ; 607,7 ; 621,3$; 622,$7 ; 629,9 ; 649,9 ; 710,27$; 717,2; P.Lond.IIS.152,11;210,9; 212,3; 317,23; CPR.14, 8; 17,10; 63,$6 ; 139,15 ; 202,7$ (?); P. Oxy. 95, 15; P. Fay. 93, 1; 212).

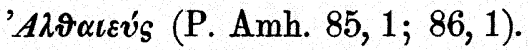

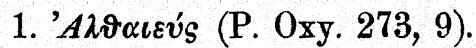

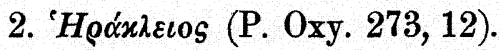

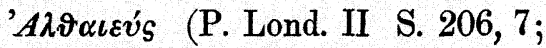
P. 0xy. 100, 4).

The list of demes, including those enumerated above, as well as those which cannot be assigned to any tribe, is as follows:

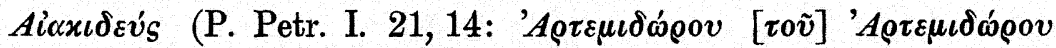

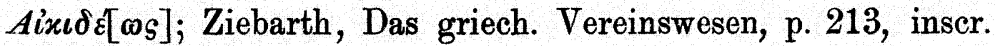

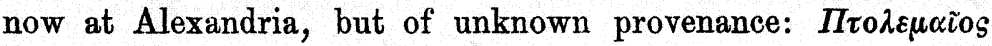

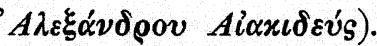

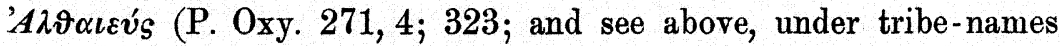

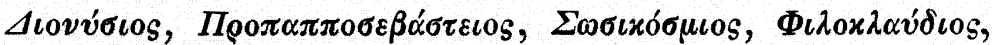
$\Phi v \lambda \alpha \xi \iota v \alpha \lambda \alpha \dot{\sigma} \sigma \varepsilon \iota 0 s$, and [? $N \varepsilon] \iota \lambda \alpha \nu \alpha \beta \alpha \dot{\tau} \iota \mathrm{los})$.

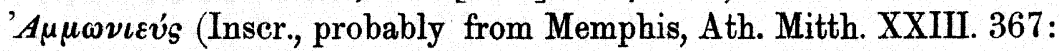

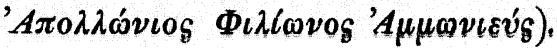

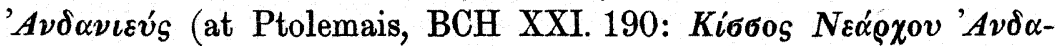

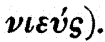

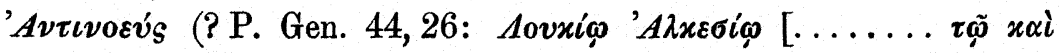
'A] $\nu \tau \iota \nu 0 \varepsilon \tilde{\imath})$.

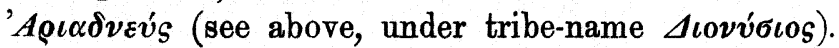

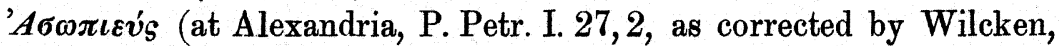
GGA, 1895, p. 143; the reading is doubtful.).

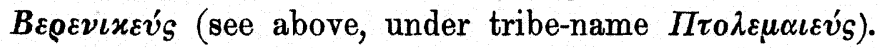

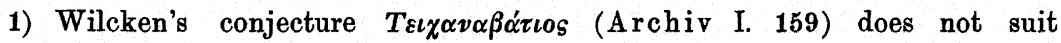
the papyrus, which plainly has $\lambda$ as its third letter. The Oxyrhynchus papyrus, according to the editors' corrected reading (0xy. Pap. II. 319) has [.] $\varepsilon \iota \tau \alpha \nu \alpha \beta \alpha \tau \varepsilon \iota \omega$. Perhaps $N \varepsilon \imath \lambda \alpha \nu \alpha \beta \alpha^{\prime} \tau \iota$ s, the remains of the first letter in the London papyrus being not inconsistent with $N$, though they do not naturally suggest it. 


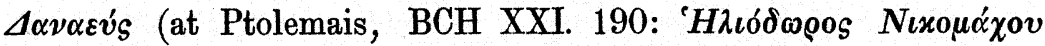
$\triangle \alpha \nu \alpha \varepsilon v_{s} ; c f$. P. Petr. I. 24, 2, and Wilcken, l. c. p. 141).

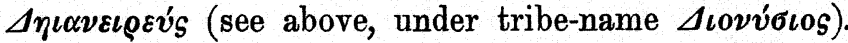

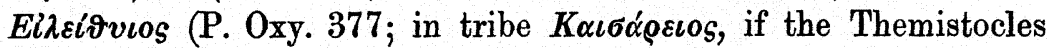
mentioned in 373 and 377 is the same).

'Edevбivios (P. Petr. I. 13, 2).

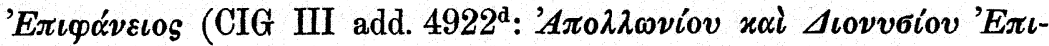

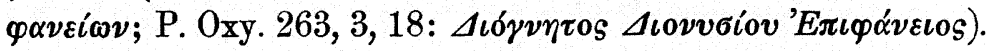

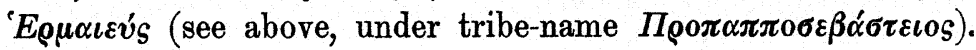

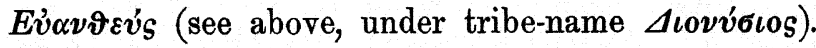

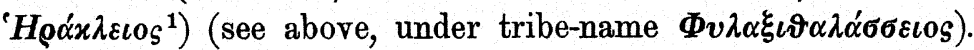

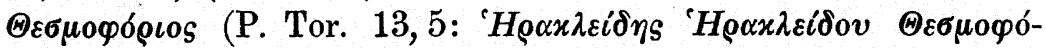
oıs).

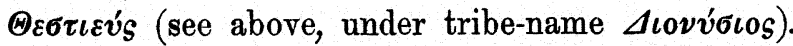

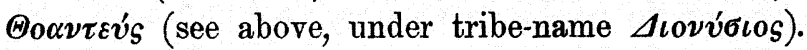

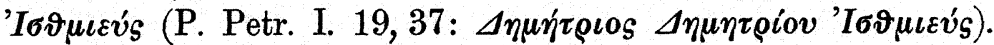

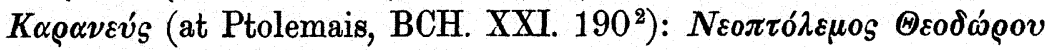

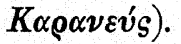

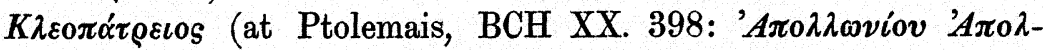

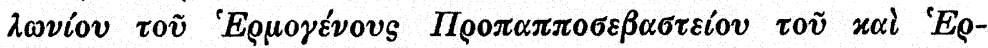

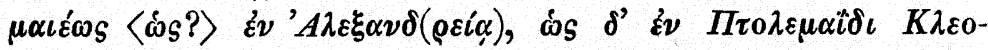
$\left.\pi \alpha \tau \rho \varepsilon i o v) .{ }^{3}\right)$

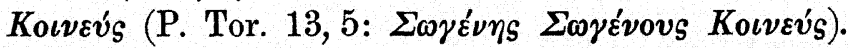

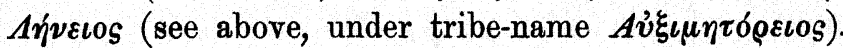

$\Lambda \eta \tau \omega \varepsilon v^{\prime}$ (at Alexandria, Tryphon ap. Steph. Byz.).

Ma@øvev́s (P. Oxy. 243, 1; 261, 8; BGU 748 III. 2, 14; P. Berl. 1893, of. Wilcken, GGA, 1895, p. 136, note 2; Ath. Mitth. XIX. 220; and see above, under tribe-names Aıovv́бıs and

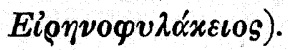

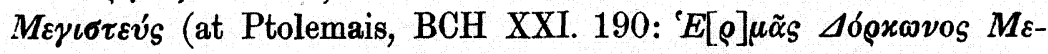

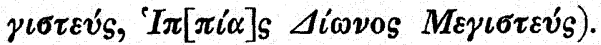

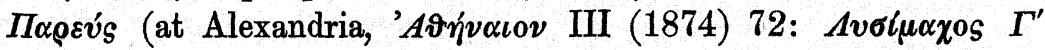

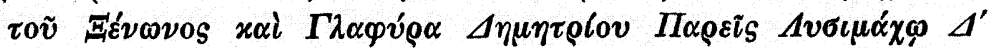

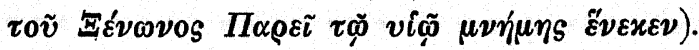

1) Dr. Crönert calls attention to the recurrence of this deme-name in several inscriptions from Delos (BCH VII. 280, VIII. 143, 146, 488, XXIII. 68, 75), and observes that Loewy's reference (Künstlerinschr. 312) of it to a town called Heracleia is erroneous.

2) This inscription, edited by Iouguet, is a decree in honour of the six prytaneis for the year, whose names are recited with their demes.

3) [So nach dem Abklatsch. S. oben S. 74, 3. D. Red.] 


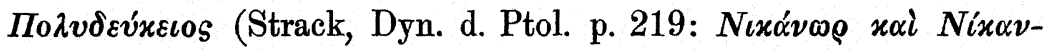

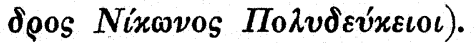

$\Sigma \alpha \varrho \alpha \pi i \delta \varepsilon \iota$ s (at Alexandria, Bull. Alex. II (1899), 63: $\Sigma \alpha \rho \alpha \pi i \omega \nu$

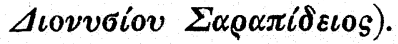

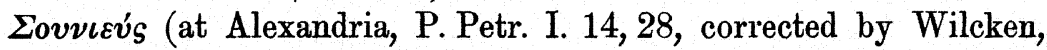
GGA, 1895, p. 136).

$\Sigma \tau \alpha \varphi v \lambda \varepsilon v_{s}$ (see above, under tribe-name $\Delta \iota v^{v} \sigma \iota \sigma_{\text {s). }}$

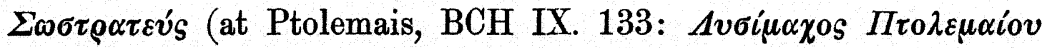

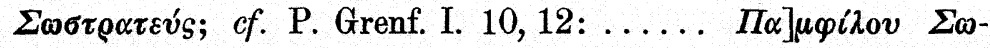
$\sigma \tau \rho \alpha \tau \varepsilon \tilde{i})$.

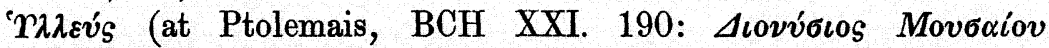

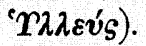

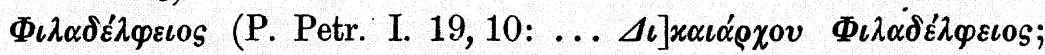

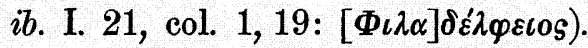

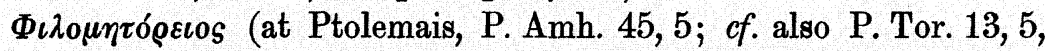
CIG III. 4678. The latter is an inscr. from Alexandria, hence the deme is probably Alexandrian as well as Ptolemaitan).

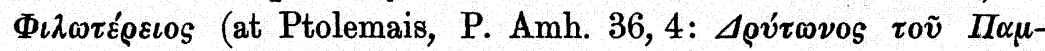

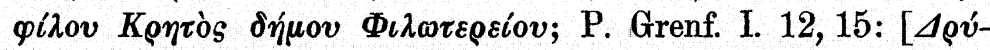

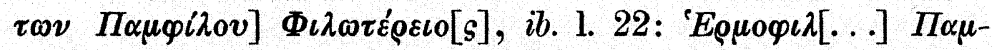

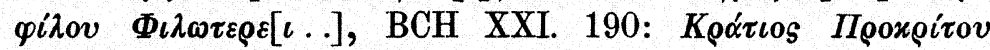
$\left.\Phi_{\iota}[\lambda] \omega \tau \varepsilon \dot{\varepsilon \varepsilon}[\iota] \circ s\right)$.

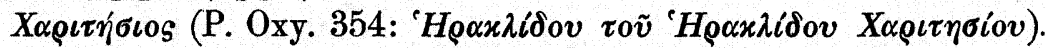

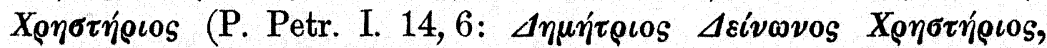
cf. Wilcken, GGA, 1895, p. 136).

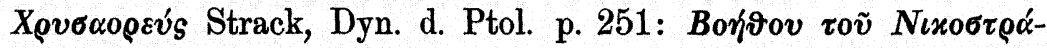

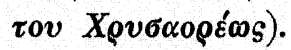

From this list it appears that we have three tribe-names which

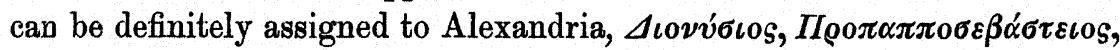

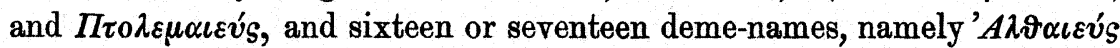

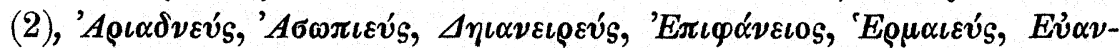

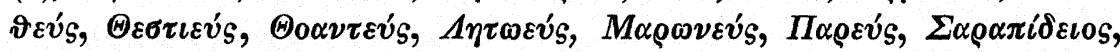

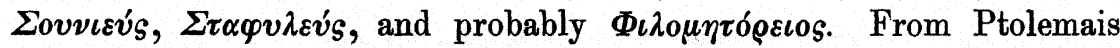

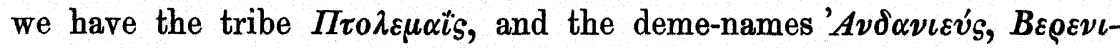

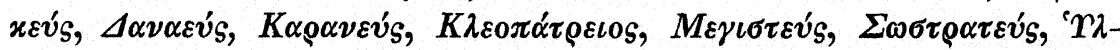

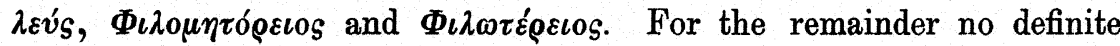
evidence is at present forthcoming, but, except in the case of documents from Upper Egypt, the presumption is that the demes named belong to Alexandria, since the citizenship of that town is likely to have been more widely distributed than that of Naucratis, Antinoë, or 
Ptolemais, especially when it is remembered that before the time of Caracalla the possession of Alexandrian citizenship was the essential preliminary to the obtaining the citizenship of Rome. In particular, it seems safe to assume that the name $\Phi v \lambda \alpha \xi \iota \imath \alpha \lambda \alpha^{\prime} \sigma \sigma \varepsilon \iota$ o $_{\text {s }}$ belongs to Alexandria, since it is only appropriate to a coast town.

If the list that has been given above is complete, it is in great measure due, as indicated previously, to the help of Dr. Crönert and Prof. Wilcken; but now that attention has been called to the subject it is probable that other scholars will be able to increase it considerably in the future, as more evidence comes to light.

London.

F. G. Kenyon. 